\title{
HortSyst: A dynamic model to predict growth, nitrogen uptake, and transpiration of greenhouse tomatoes
}

\author{
Antonio Martínez-Ruiz ${ }^{1}$, Irineo L. López-Cruz ${ }^{2}$, Agustín Ruiz-García ${ }^{3}$, Joel Pineda-Pineda ${ }^{4 *}$, \\ and J. Víctor Prado-Hernández ${ }^{4}$ \\ 'Instituto Nacional de Investigaciones Forestales, Agrícolas y Pecuarias (INIFAP), Campo Experimental San Martinito, Puebla, \\ C.P. 74100 , México. \\ ${ }^{2}$ Universidad Autónoma Chapingo, Posgrado en Ingeniería Agrícola y Uso Integral del Agua, Texcoco C.P. 56230, México. \\ ${ }^{3}$ Universidad Autónoma Chapingo, Departamento de Irrigación, km 38.5 Carretera México-Texcoco, C.P. 56230, Texcoco, México. \\ ${ }^{4}$ Universidad Autónoma Chapingo, Departamento de Suelos, km 38.5 Carretera México-Texcoco, C.P. 56230, Texcoco, México. \\ "Corresponding author (pinedapjoel@yahoo.com.mx).
}

Received: 10 May 2018; Accepted: 8 November 2018; 10.4067/S0718-58392019000100089

\begin{abstract}
The HortSyst model is a new discrete time model for describing the dynamics of photo-thermal time (PTI), total dry matter production (DMP), $\mathrm{N}$ uptake $\left(\mathrm{N}_{\mathrm{up}}\right.$ ), leaf area index (LAI), and evapotranspiration $\left(\mathrm{ET}_{\mathrm{c}}\right)$ for greenhouse crops. The first three variables are considered as state variables and the latter two are conceptualized as output variables. This model was developed as a tool for decision support systems in Mexican greenhouses for the application of $\mathrm{N}$ and water in tomato (Solanum lycopersicum L.) production. The HortSyst has 13 parameters. It was used to calibrate the model and estimate the correct parameter values for the crop season. An experiment was carried out to test model predictions in a greenhouse during the autumn-winter season in Chapingo, Mexico. Tomato 'CID F1' was grown in a hydroponic system and plants were distributed with a density of 3.5 plants $\mathrm{m}^{-2}$. The tomato crop was transplanted on 21 August 2015. A weather station was installed inside the greenhouse to measure temperature, relative humidity, and global radiation. The HortSyst model provides an excellent predictive quality for DMP, $\mathrm{N}_{\mathrm{up}}, \mathrm{LAI}$, and $\mathrm{ET}_{\mathrm{c}}$ according to the statistics. Values for bias (BIAS) were DMP (-3.897), $\mathrm{N}_{\text {up }}(-0.071)$, LAI (0.026), and $\mathrm{ET}_{\mathrm{c}}$ (3.647), values for root mean square error (RMSE) were DMP (14.543), $\mathrm{N}_{\text {up }}(0.500)$, LAI (0.100), and $\mathrm{ET}_{\mathrm{c}}$ (39.330), and values for modeling efficiency (EF)were DMP (0.996), $\mathrm{N}_{\text {up }}$ (0.991), LAI (0.998), and $\mathrm{ET}_{\mathrm{c}}(0.815)$. The model proposed and described in this paper can be integrated as a decision support tool for $\mathrm{N}$ supply and irrigation management in greenhouse production systems.
\end{abstract}

Key words: Decision support system, extraction curve, potential growth model, Solanum lycopersicum, water consumption.

\section{INTRODUCTION}

Plant growth modeling has become a key research activity, particularly in the fields of agriculture, forestry, and the environmental sciences. The development of plant growth models has progressed a great deal during the last two decades due to the growth of computer power and resources as well as the sharing of experiences between biologists, mathematicians, and computer scientists. The use of an interdisciplinary approach is necessary to advance research in plant growth modeling and simulation (Fourcaud et al., 2008). Efficient intensive agriculture management must consider the factors that determine crop production potential and their interactions. The integration of these factors under the systems approach based on growth simulation models allows the design of management practices aimed at increasing productivity 
by minimizing environmental impact caused by agricultural activity. Several mathematical models have been developed to increase knowledge about cropping systems in greenhouse crops and search for practical applications. Specifically, the following models have been proposed for tomatoes: TOMGRO (Bacci et al., 2012), TOMSIM (Marcelis et al., 2009), and TOMPOUSSE (Rodríguez et al., 2016), which have helped to simulate the behavior of production systems. However, some of these models are very complex because they involve many state variables, input variables, or parameters that make their implementation difficult. For example, the TOMGRO ver. 1.0 model has 69 state variables; TOMGRO ver. 3.0 has 574 state variables, and the simplified version of this same model has 5 state variables and 29 parameters (VazquezCruz et al., 2014). Other simpler models for greenhouse crops have been developed for region-specific crop systems such as the VegSyst model (Gallardo et al., 2014; 2016). However, it has the disadvantage that the concepts applied in the model are for open field crops (heat units and crop growth coefficient for evapotranspiration) and do not consider the effect of density and leaf area index (LAI) on the physiological variables. It is necessary to develop models to have optimal control of production system management that have the capacity to represent the interactions between the development of the crop, climatic conditions, and physiological processes of water and nutrient uptake. The effect of crop transpiration $\left(\mathrm{ET}_{\mathrm{c}}\right)$ and irrigation management on nutritional absorption needs to be taken into account to find which concentration of the optimal nutrient solution is the most desirable in a production system. Dissolved ions in the nutrient solution are transported from the root through mass flow in which $\mathrm{ET}_{\mathrm{c}}$ is the process that provides the necessary force to move these ions (Barker and Pilbeam, 2015). The perfect synchronization between the amounts of water required for growth and the nutritional demand of the crop depend on environmental conditions; therefore, a mathematical model could allow a highly efficient use of the water supply in greenhouse crops. Nowadays, some irrigation scheduling of hydroponic culture in greenhouses is based either on clock timing or by accumulated solar radiation, although these strategies are not flexible enough to satisfy the different crop water requirements throughout the day and during the season. This is because both irrigation programming methods do not take into account the influence of vapor pressure deficit (VPD).

The HortSyst model is a new dynamic discrete time model that predicts photo-thermal time (PTI), total dry matter production (DMP), $\mathrm{N}$ uptake $\left(\mathrm{N}_{\mathrm{up}}\right), \mathrm{LAI}$, and transpiration $\left(\mathrm{ET}_{\mathrm{c}}\right)$. This model was initially developed by modifying the structure of the VegSyst model (Giménez et al., 2013; Gallardo et al., 2014; 2016) proposed for greenhouse crops. However, the number of modifications was increasingly significant and led to a new model that was much simpler and had a predictive quality equal or better than the VegSyst model. The objective of the present study was to describe the HortSyst mathematical model that was developed as a tool for growers related to $\mathrm{N}$ supply from the simulation of daily DMP and irrigation programming using hydroponic tomato (Solanum lycopersicum L.) transpiration in a greenhouse. In addition, an LAI model was included in the simulation, which was estimated by the PTI concept (Xu et al., 2010). Parameter calibration of the HortSyst model was also carried out.

\section{MATERIALS AND METHODS}

\section{HortSyst model description}

The HortSyst model is a nonlinear dynamic growth model for tomato (Solanum lycopersicum L.) hydroponic systems in greenhouses. This model was developed and adapted as a tool for decision support systems in Mexican greenhouses for the application of $\mathrm{N}$ and water in tomato production. The model assumes that crops have no water and nutrient limitations, that the crop isalso pest- and disease-free, and was cultivated under agronomic activity management similar to the one found in commercial greenhouses.

The HortSyst model predicts crop biomass production (DMP, $\left.\mathrm{g} \mathrm{m}^{-2}\right), \mathrm{N}$ uptake $\left(\mathrm{N}_{\mathrm{up}}, \mathrm{g} \mathrm{m}^{-2}\right)$, PTI $\left(\mathrm{MJ} \mathrm{d}^{-1}\right)$ as state variables, and $\mathrm{ET}_{\mathrm{c}}\left(\mathrm{kg} \mathrm{m}^{-2}\right)$ and $\mathrm{LAI}\left(\mathrm{m}^{2} \mathrm{~m}^{-2}\right)$ as output variables. The model input variables were hourly measurements of air temperature $\left({ }^{\circ} \mathrm{C}\right), \mathrm{RH}(\%)$, and solar radiation integration $\left(\mathrm{W} \mathrm{m}^{-2}\right)$; it has 13 parameters and the nominal parameters for the tomato crop are listed in Table 1. The Forrester diagram (Figure 1) summarizes the functional relationship between the model components as inputs, outputs, parameters, and state variables.

The HortSyst model also predicts in discrete time, namely, by difference equations that express the behavior of the three state variables: PTI (Equation [1]), total DMP (Equation [2]), and $\mathrm{N}_{\text {up }}$ (Equation [3]):

$$
\begin{gathered}
D M P(j+1)=D M P(j)+\Delta D P M \\
P T I(j+1)=P T I(j)+\Delta P T I \\
N_{u p}(j+1)=N_{u p}(j)+\Delta N_{u p}
\end{gathered}
$$


where the values of each variable in discrete time $j+1$ are calculated by adding the values of the variables in the previous discrete time $j$ plus the rate of change corresponding to each variable. The PTI is defined as the state variable that joins the effect of radiation and temperature on the crop because, from the climatic point of view, these variables in the greenhouse are not as strongly correlated as in the open field (Dai et al., 2006; Xu et al., 2010). In contrast, other researchers have modeled LAI as a function of time or as a function of degree days (Medrano et al., 2008; Chin et al., 2011; Massa et al., 2011; Carmassi et al., 2013); others have used days after transplanting (Medrano et al., 2005; Ta et al., 2011) or specific leaf area (Castañeda-Vera et al., 2015). In the HortSyst model, PTI is the independent variable in the calculation of crop LAI. In the VegSyst model, thermal time is the state variable that drives the daily calculation of DMP, $\mathrm{N}_{\mathrm{up}}$, and $\mathrm{ET}_{\mathrm{c}}$. However, it is important to consider radiation because it directly influences crop growth (DMP) and development (morphogenesis).

Table 1. Model parameters used for the HortSyst model under greenhouse growing conditions.

\begin{tabular}{|c|c|c|c|c|c|c|}
\hline Output & $\mathrm{Nr}$ & Parameter & Symbol & Units & $\begin{array}{l}\text { Nominal value } \\
\text { (autumn-winter) }\end{array}$ & Source \\
\hline \multirow[t]{5}{*}{ DMP } & 1 & Maximum temperature & $\mathrm{T}_{\max }$ & ${ }^{\circ} \mathrm{C}$ & 35.00 & Chu et al., 2009 \\
\hline & 2 & Minimum temperature & $\mathrm{T}_{\min }$ & ${ }^{\circ} \mathrm{C}$ & 10.00 & Chu et al., 2009 \\
\hline & 3 & Lower optimal temperature & $\mathrm{T}_{\mathrm{ob}}$ & ${ }^{\circ} \mathrm{C}$ & 17.00 & \\
\hline & 4 & Upper optimal temperature & $\mathrm{T}_{\text {оu }}$ & ${ }^{\circ} \mathrm{C}$ & 24.00 & \\
\hline & 5 & Radiation use efficiency & RUE & $\mathrm{g} \mathrm{MJ}^{-1}$ & 4.01 & Gallardo et al., 2014 \\
\hline \multirow[t]{2}{*}{ PTI } & 6 & Extinction coefficient & $\mathrm{k}$ & - & 0.70 & - \\
\hline & 7 & PTI initial condition & PTIini & $\mathrm{MJ} \mathrm{d}^{-1}$ & 0.025 & - \\
\hline \multirow[t]{2}{*}{$\mathrm{N}_{\mathrm{up}}$} & 8 & $\begin{array}{l}\mathrm{N} \text { concentration in dry biomass at the end of the } \\
\text { exponential growth period }\end{array}$ & $\mathrm{a}$ & $\mathrm{g} \mathrm{m}^{-2}$ & 7.55 & Gallardo et al., 2014 \\
\hline & 9 & Slope of the relationship & $\mathrm{b}$ & - & -0.15 & Gallardo et al., 2014 \\
\hline \multirow[t]{2}{*}{ LAI } & 10 & Slope of the curve & $\mathrm{c}_{1}$ & $\mathrm{~m}^{-2}$ & 2.82 & Estimated \\
\hline & 11 & Intersection coefficient & $\mathrm{c}_{2}$ & - & 74.66 & Estimated \\
\hline \multirow[t]{3}{*}{$\mathrm{ET}_{\mathrm{c}}$} & 12 & Radiative coefficient & A & - & 0.3 & Sánchez et al., 2011 \\
\hline & 13 & Daytime aerodynamic coefficient during & $\mathrm{B}_{\mathrm{d}}$ & $\mathrm{W} \mathrm{m}{ }^{-2}, \mathrm{kPa}^{-1}$ & 18.7 & Sánchez et al., 2011 \\
\hline & 14 & Nighttime serodynamic coefficient & $\mathrm{B}_{\mathrm{n}}$ & $\mathrm{W} \mathrm{m}{ }^{-2}, \mathrm{kPa}^{-1}$ & 8.5 & Sánchez et al., 2011 \\
\hline
\end{tabular}

DMP: Total DM production; PTI: photo-thermal time; $\mathrm{N}_{\mathrm{up}}$ : nitrogen uptake; LAI: leaf area index; $\mathrm{ET}_{\mathrm{c}}$ : evapotranspiration.

Figure 1. Forrester's relational diagram for the HortSyst model for a greenhouse tomato crop: input, output, state variables, and parameters of the crop model.

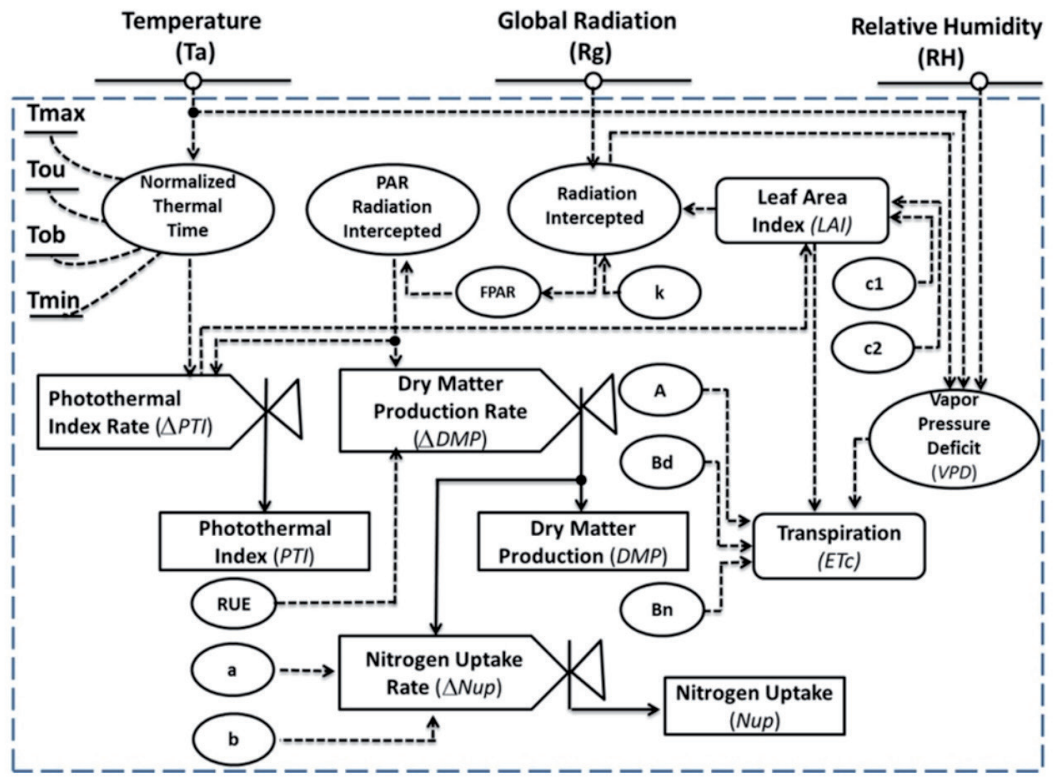


The PTI rate of change ( $\triangle \mathrm{PTI}$ ) depends on photosynthetically active radiation (PAR), normalized thermal time (TT), and the intercepted radiation fraction $\left(\mathrm{f}_{\mathrm{i}-\mathrm{PAR}}\right)$.

$$
\begin{gathered}
\Delta P T I(j)=\left(\sum_{i=1}^{24} T T(i, j)\right) / 24 \times P A R(j) \times f_{i-P A R}(j) \\
P A R=0.5 \times R_{g}
\end{gathered}
$$

where the index $i$ represents hourly calculations, index $j$ represents the daily level, PAR is photosynthetically active radiation calculated from the daily global radiation above the $\operatorname{crop}\left(R_{g}, \mathrm{~W} \mathrm{~m}^{-2}\right)$, and $T T\left({ }^{\circ} \mathrm{C}\right)$ is the normalized thermal time. Soltani and Sinclair (2012) and other researchers have used this concept, which is defined as the ratio of the rate of growth under real optimal temperature conditions and is calculated as follows:

$$
T T= \begin{cases}0 & \left(T_{a}<T_{\min }\right) \\ \left(T_{a}-T_{\min }\right) /\left(T_{o b}-T_{\min }\right) & \left(T_{\min } \leq T_{a}<T_{o b}\right) \\ 1 & \left(T_{o b} \leq T_{a} \leq T_{o u}\right) \\ \left(T_{\max }-T_{a}\right) /\left(T_{\max }-T_{o u}\right) & \left(T_{o u}<T_{a} \leq T_{\max }\right) \\ 0 & \left(T_{a}>T_{\max }\right)\end{cases}
$$

where $T_{a}\left({ }^{\circ} \mathrm{C}\right)$ is air temperature, $T_{\min }\left({ }^{\circ} \mathrm{C}\right)$ is the minimum temperature, $T_{\max }\left({ }^{\circ} \mathrm{C}\right)$ is the maximum temperature, $T_{o b}\left({ }^{\circ} \mathrm{C}\right)$ is the lower optimal temperature, and $T_{\text {ои }}\left({ }^{\circ} \mathrm{C}\right)$ is the upper optimal temperature.

The intercepted radiation fraction is calculated by the following exponential function:

$$
f_{i-P A R}=1-\exp (-k \times \operatorname{LAI}(j))
$$

where $k$ is the light extinction coefficient and LAI is calculated from the leaf area value $A_{f}\left(\mathrm{~m}^{2}\right)$. It depends on daily PTI $(\triangle \mathrm{PTI})$ expressed by a Michaelis-Menten equation expressed in Equation [8].

$$
\operatorname{LAI}(j)=\frac{c_{1} P T I(j)}{c_{2}+P T I(j)} d
$$

where $c_{l}\left(\mathrm{~m}^{-2}\right)$ and $c_{2}$ are parameters of the Michaelis-Menten equation and $d$ (plants $\left.\mathrm{m}^{-2}\right)$ is crop density.

The model uses a classical concept approach and efficient radiation application (Rodríguez et al., 2016), which allow calculating the total DMP ( $\triangle \mathrm{DMP})$ daily increase as a function of PAR in Equation [5], crop characteristics, such as LAI, in Equation [8], and the radiation use efficiency parameter (RUE, $\mathrm{g} \mathrm{MJ}^{-1}$ ). This approach has been applied by several researchers (Shibu et al., 2010; Soltani and Sinclair, 2012; Gallardo et al., 2016).

$$
\triangle D M P(j)=R U E \times f_{\text {i-PAR }} \times P A R(j)
$$

The $\triangle \mathrm{DMP}$ value is accumulated daily as in Equation [2]. As for the model, it is not necessary to estimate the partitioning of DMP in different plant organs because crop nutrient extraction occurs in the total produced biomass (Lemaire et al., 2007) for nutrition management purposes.

Once daily DMP is calculated, daily $\mathrm{N}_{\text {up }}$ can be calculated by Equations [10] and [11] (Tei et al., 2002) and is accumulated with Equation [3], so that total $\mathrm{N}$ extraction is obtained throughout the crop growing period ( $\triangle \mathrm{DMP})$ :

$$
\begin{gathered}
\% \Delta N(j)=a \times(\Delta D M P(j))^{-b} \\
\Delta N_{u p}(j)=(\% N(j) / 100) \times \Delta D M P(j)
\end{gathered}
$$

where $\Delta N_{u p}$ is daily $\mathrm{N}_{\text {up }}\left(\mathrm{g} \mathrm{m}^{-2}\right), a$ and $b$ are the parameters of the equation, and $\Delta \mathrm{DMP}$ is the increase in total daily $\operatorname{DMP}\left(\mathrm{g} \mathrm{m}^{-2}\right)$.

Finally, $\mathrm{ET}_{\mathrm{c}}\left(\mathrm{kg} \mathrm{m}^{-2}\right)$ is calculated hourly by the Baille equation as used by Sánchez et al. (2011) and Martinez-Ruiz et al. (2012), and which has been widely applied to schedule irrigation events in greenhouse crops (Massa et al., 2011; Martinez-Ruiz et al., 2012; Carmassi et al., 2013). The Baille transpiration model requires global radiation $\left(\mathrm{R}_{\mathrm{g}}\right)$ and VPD data, which is calculated with $T_{a}$, RH, and LAI values. The equations for $\mathrm{ET}_{\mathrm{c}}$ in the HortSyst model are described as follows:

$$
\begin{gathered}
E T c(i)=A \times(1-\exp (-k \operatorname{LAI}(j))) \times R g(\mathrm{i})+\operatorname{LAI}(j) V P D(i) B_{(d, n)} \\
E T c(\mathrm{j}+1)=\sum_{i=1}^{24} \operatorname{ETc}(\mathrm{i})
\end{gathered}
$$


where $E T_{c}(j+1)\left(\mathrm{kg} \mathrm{m}^{-2} \mathrm{~d}^{-1}\right)$ is daily accumulated transpiration, $E T_{c}(i)\left(\mathrm{g} \mathrm{m}^{-2} \mathrm{~h}^{-1}\right)$ is hourly transpiration, $R_{g}$ is the hourly incidence of global solar radiation ( $\left.\mathrm{W} \mathrm{m}^{-2}\right), V P D$ is vapor pressure deficit, and $A$ (dimensionless) refers to the radiative parameter; furthermore, $B_{d}$ and $B_{n}\left(\mathrm{~W} \mathrm{~m}^{2} \mathrm{kPa}^{-1}\right)$ are the parameters of the aerodynamic term in Equation [12] for day and night, respectively.

\section{The computational model}

The HortSyst is currently programmed in the MATLAB-R2015a version (MathWorks Inc., Natick, Massachusetts, USA) computing environment. The dynamic equations are coded inside a MATLAB subroutine (function). Two iterative loops allow computing daily and hourly calculations. The outputs of the subroutine are the variables PTI, total DMP, $\mathrm{N}_{\mathrm{up}}, \mathrm{ET}_{\mathrm{c}}$, and LAI. The input variables of the subroutine are the model parameters (Table 1) and climatic variables (Figures 2 and 3). The main program (MATLAB script) calls the subroutine and generates graphs or other calculations necessary to run the simulations.

\section{Description of tomato growth experiment}

The experiment was carried out under greenhouse conditions during the autumn-winter season (111 days) and was located at the University of Chapingo (19²9' N, 98 53' W; 2240 m a.s.l.), Mexico. Tomato 'CID F1' were grown in a hydroponic system using volcanic sand as substrate and fertilized with Steiner nutrient solution in which macronutrient concentrations

Figure 2. Daily mean global radiation measured inside a greenhouse located in Chapingo, Mexico, during the 2015 autumn-winter season.

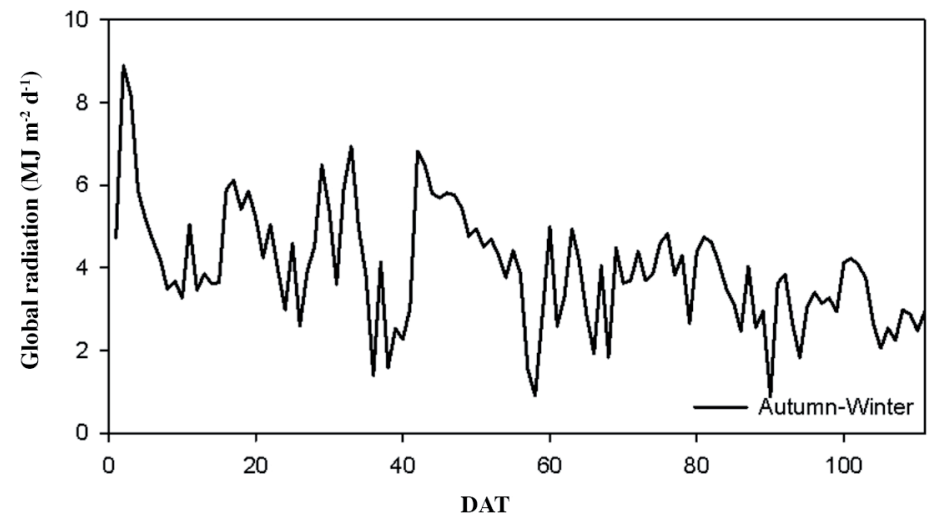

DAT: Days after transplanting.

Figure 3. Daily mean air temperature and relative humidity measured inside a greenhouse located in Chapingo, Mexico, during the 2015 autumn-winter season.

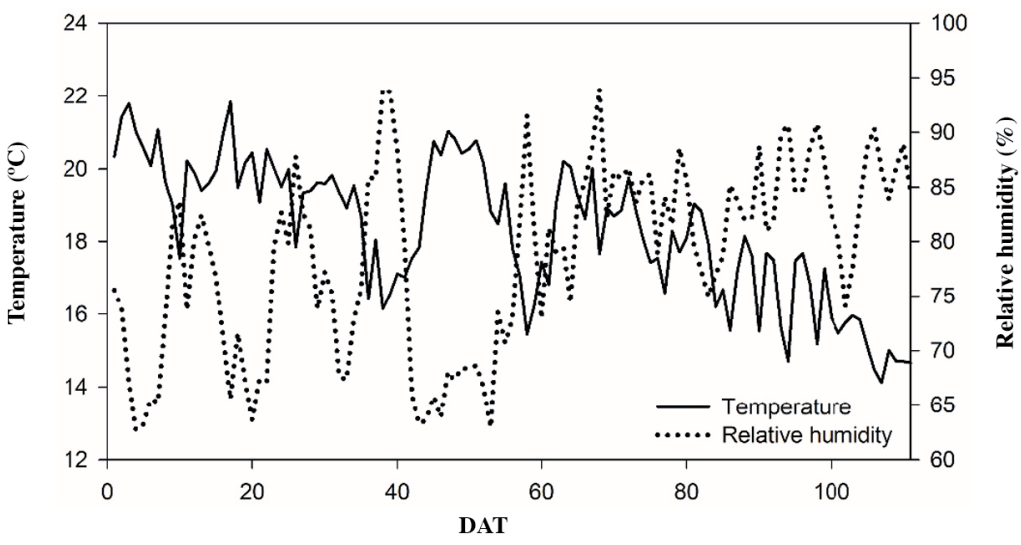

DAT: Days after transplanting. 
were $168 \mathrm{mg} \mathrm{NO}_{3}^{-} \mathrm{L}^{-1}, 45 \mathrm{mg} \mathrm{H}_{2} \mathrm{PO}_{4}^{-\mathrm{L}^{-1}}, 292.5 \mathrm{mg} \mathrm{K}^{+} \mathrm{L}^{-1}, 180 \mathrm{mg} \mathrm{Ca}^{2+} \mathrm{L}^{-1}, 48.6 \mathrm{mg} \mathrm{Mg}^{2+} \mathrm{L}^{-1}, 224 \mathrm{mg} \mathrm{SO}_{4}{ }^{2-} \mathrm{L}^{-1}$; micronutrient concentrations were $2 \mathrm{mg} \mathrm{Fe}^{2+} \mathrm{L}^{-1}, 1 \mathrm{mg} \mathrm{Mn}^{2+} \mathrm{L}^{-1}, 0.2 \mathrm{mg} \mathrm{Zn}^{2+} \mathrm{L}^{-1}, 0.1 \mathrm{mg} \mathrm{Cu}^{2+} \mathrm{L}^{-1}$ (Pineda-Pineda et al., 2009). Plants were distributed with 3.5 plants $\mathrm{m}^{-2}$ density. For the experiment, tomato seeds were sown on 18 July 2015 and plants were transplanted on 21 August 2015 in a chapel type $8 \times 8 \mathrm{~m}$ greenhouse. A weather station (HOBO, Onset, Bourne, Massachusetts, USA) was installed inside the greenhouse. The $T_{a}$ and RH were measured with an S-TMB-M006 model sensor (Onset) placed at a height of $1.5 \mathrm{~m}$. The $\mathrm{R}_{\mathrm{g}}$ was measured with an S-LIB-M003 sensor (HOBO, Onset) located $3.5 \mathrm{~m}$ aboveground. Both sensors were connected to a data logger U-30-NRC model (HOBO) in which environmental variable data were recorded every minute and processed for hourly use.

Three plants were randomly chosen for the samples each 10 days to measure total DM, $\mathrm{N}_{\text {up }}$ accumulation, and LAI. Plants were dried at $70{ }^{\circ} \mathrm{C}$ for $72 \mathrm{~h}$, and $\mathrm{N}$ was determined by the micro-Kjeldahl method. The LAI was determined by a nondestructive procedure, which consisted of randomly taking four plants to measure plant leaf width and length, while total leaf area was measured with a plant canopy analyzer (LAI-3100, LI-COR, Lincoln, Nebraska, USA). Nonlinear regression models were fitted using the measurements to estimate LAI. Crop transpiration was measured every minute with a weighing lysimeter located in the central row of the greenhouse; the device includes an electronic balance $(120 \mathrm{~kg}$ scale capacity and $\pm 5 \mathrm{~g}$ resolution) equipped with a tray carrying four plants. Weight loss measured with the electronic balance was assumed to be equal to crop transpiration.

\section{Model calibration and goodness-of-fit statistics}

The nominal parameters listed in Table 1 were used to judge the predictive quality of the HortSyst model. The bias (BIAS), root mean square error (RMSE), and modeling efficiency (EF) statistics (Table 2) were considered to evaluate the simulation performance of the calibrated and non-calibrated model, and 1:1 plots between simulated and measured data were used.

An appropriate method to perform model calibration is nonlinear least squares estimation. A parameter vector $p$ minimizes the sum of squared errors (Vazquez-Cruz et al., 2014):

$$
\begin{gathered}
\hat{p}=\arg \min J(\mathrm{p}) \\
J(p)=\sum_{h=1}^{L} \sum_{i=1}^{M} w_{y}\left[\bar{y}_{h}\left(t_{i}, p\right)-y_{h}\left(t_{i}\right)\right]^{2}
\end{gathered}
$$

where $w_{h}$ is the relative weight of each output, $\bar{y}_{h}\left(t_{i}, p\right)$ is the simulated output, $y_{h}$ in time $t_{i}, y_{h}\left(t_{i}\right)$ is the measurement $y_{h}\left(t_{i}\right)$ in time $t_{i}, L=5$ is the number of outputs, $M$ is the number of samples during the crop period $y_{h}$ in time $t_{i}, p$ is the calibration parameter set, and $\hat{p}$ is the parameter that reduces $J(p)$ to a minimum.

The performance of the non-calibrated and calibrated models was evaluated by BIAS, whereas RMSE and EF statistics were defined as follows (Wallach et al., 2014):

$$
B I A S=\left(\frac{1}{N}\right) \sum_{i=1}^{N}\left(Y_{i}-\hat{Y}_{i}\right)
$$

Table 2. Summary of statistical index (BIAS, RMSE and EF) results used to evaluate the performance of the HortSyst model simulation for DMP, $\mathrm{N}_{\mathrm{up}}, \mathrm{ET}_{\mathrm{c}}$, and LAI during the 2015 autumn-winter season.

\begin{tabular}{lccccc}
\hline Neural network & $\begin{array}{c}\text { Non-calibrated } \\
\text { HortSyst }\end{array}$ & $\begin{array}{c}\text { Calibrated } \\
\text { HortSyst }\end{array}$ & & $\begin{array}{c}\text { Non-calibrated } \\
\text { HortSyst }\end{array}$ & $\begin{array}{c}\text { Calibrated } \\
\text { HortSyst }\end{array}$ \\
\hline Statistics & \multicolumn{2}{c}{ DMP $\left(\mathrm{g} \mathrm{m}^{-2}\right)$} & & Statistics & \multicolumn{2}{c}{ LAI $\left(\mathrm{m}^{-2} \mathrm{~m}^{-2}\right)$} \\
BIAS & 37.443 & -3.897 & BIAS & -0.028 & 0.026 \\
RMSE & 53.599 & 14.543 & RMSE & 0.099 & 0.100 \\
EF & 0.952 & 0.996 & EF & 0.998 & 0.998 \\
& $-\mathrm{N}_{\text {up }}\left(\mathrm{g} \mathrm{m}^{-2}\right)$ & & & \multicolumn{2}{c}{$\mathrm{ET}_{\mathrm{c}}\left(\mathrm{g} \mathrm{m}^{-2} \mathrm{~h}^{-1}\right)$} \\
BIAS & -0.551 & -071 & BIAS & 20.618 & 3.647 \\
RMSE & 3.179 & 0.500 & RMSE & 46.417 & 39.330 \\
EF & 0.635 & 0.991 & EF & 0.743 & 0.815 \\
\hline
\end{tabular}

DMP: Total dry matter production; $\mathrm{N}_{\mathrm{up}}$ : nitrogen uptake; $\mathrm{ET}_{\mathrm{c}}$ : evapotranspiration; LAI: leaf area index; BIAS: bias; RMSE: root mean square error; EF: modeling efficiency. 


$$
\begin{aligned}
& \text { RMSE }=\sqrt{\left(\frac{1}{N}\right) \sum_{i=1}^{N}\left(Y_{i}-\hat{Y}_{i}\right)^{2}} \\
& E F=1-\frac{\sum_{i=1}^{N}\left(Y_{i}-\hat{Y}_{i}\right)^{2}}{\sum_{i=1}^{N}\left(Y_{i}-\bar{Y}_{i}\right)^{2}}
\end{aligned}
$$

where the number of measurements is $N, Y_{i}$ is the measured value for situation $i$, and $\bar{Y}_{i}$ is the corresponding value predicted by the model.

\section{RESULTS}

\section{Simulation of HortSyst model Input variables}

The $\mathrm{R}_{\mathrm{g}}, \mathrm{T}_{\mathrm{a}}$, and RH used in the HortSyst model simulations for the autumn-winter season are shown in Figures 2 and 3. The nominal values of the model parameters are given in Table 1. According to the measured data in Figure 2, the amount of $\mathrm{R}_{\mathrm{g}}$ accumulated in the autumn-winter season is too low; most days of the rainy period are cloudy. In addition, the type of greenhouse where the experiment was carried out strongly affects radiation interception because of the shade cover placed on the roof of the greenhouse; the highest daily measured value of $\mathrm{R}_{\mathrm{g}}$ was $8.89 \mathrm{MJ} \mathrm{m}^{-2} \mathrm{~d}^{-1}$ (mean $3.99 \mathrm{MJ} \mathrm{m}^{-2} \mathrm{~d}^{-1}$ and minimum $\left.0.88 \mathrm{MJ} \mathrm{m}^{-2} \mathrm{~d}^{-1}\right)$.

Figure 3 shows the daily mean of $\mathrm{T}_{\mathrm{a}}$ and RH during the crop cycle; the maximum measured temperature was $21.83{ }^{\circ} \mathrm{C}$ (mean $18.31{ }^{\circ} \mathrm{C}$ and minimum $14.12{ }^{\circ} \mathrm{C}$ ) and the maximum $\mathrm{RH}$ recorded was $93.98 \%$ (mean $78.58 \%$ and minimum $62.59 \%$ ) during the whole crop cycle.

\section{Dry matter production (DMP)}

Figure 4a illustrates the DMP simulations by the calibrated and non-calibrated HortSyst model. The RUE nominal value was $4.01 \mathrm{~g} \mathrm{MJ}^{-1}$ (Gallardo et al., 2014) and the RUE value from calibration was $4.86 \mathrm{~g} \mathrm{MJ}^{-1}$. Simulations followed the trend of values measured in the laboratory. Accumulated non-calibrated total DMP values simulated at the end of the crop cycle were $587.370 \mathrm{~g} \mathrm{~m}^{-2}$ and $697.290 \mathrm{~g} \mathrm{~m}^{-2}$ for the calibrated model compared with a measured value of $673.380 \mathrm{~g} \mathrm{~m}^{-2}$. According to the statistics (Table 2), the BIAS value of the non-calibrated model simulations indicates an underestimation of the predicted values: on the other hand, the BIAS value for the calibrated model indicates a slight overestimation of the predicted values of the model. The RMSE between the non-calibrated and calibrated model was reduced by more than

Figure 4. a) Time course of simulated and measured total dry matter production values (DMP) with the calibrated and non-calibrated HortSyst model for a greenhouse tomato crop grown in Chapingo, Mexico. b) 1:1 plot for values simulated by the calibrated model and measured values.
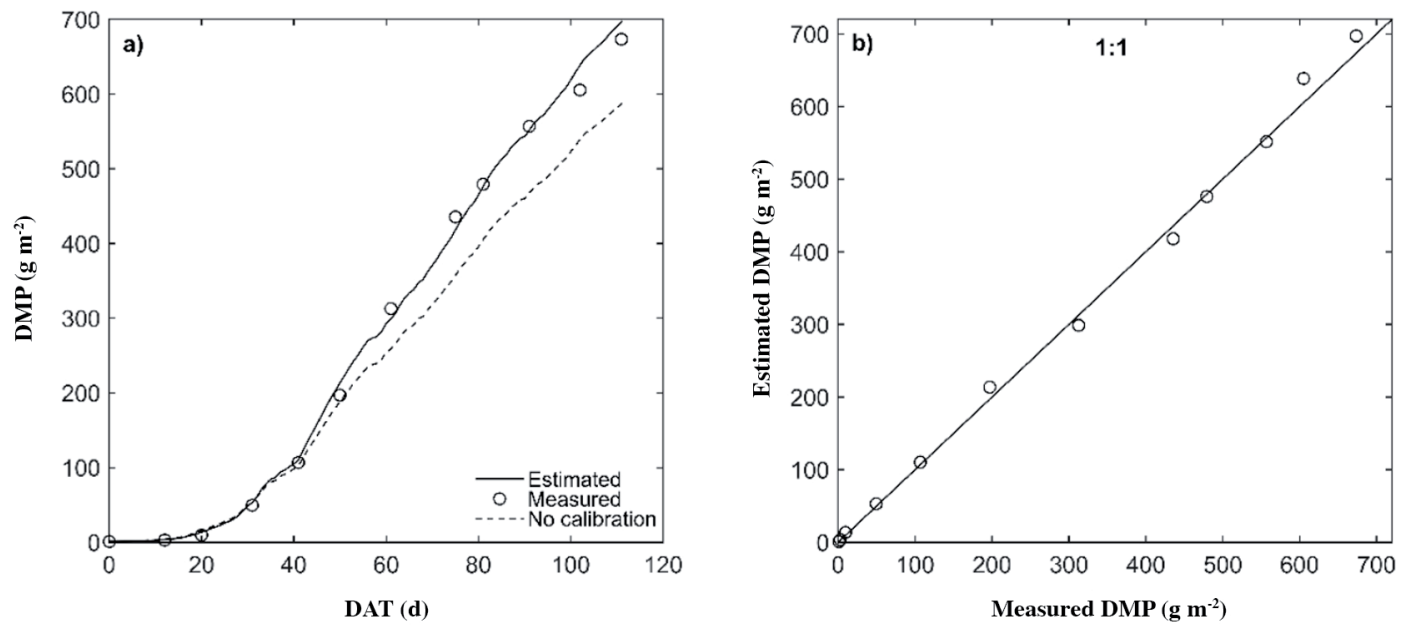

DAT: Days after transplanting. 
three times. The EF values also significantly improved when the model was calibrated; Figure 4a displays how the model estimations and measurements coincide. The 1:1 plot in Figure $4 \mathrm{~b}$ confirms this. In the experiment, total DMP initially exhibited exponential growth followed by an approximately linear growth phase, which is the expected growth pattern.

\section{Nitrogen uptake $\left(\mathbf{N}_{\text {up }}\right)$}

Figure 5a compares the HortSyst model measured and predicted values for $\mathrm{N}_{\text {up }}$ during the crop cycle. In the present study, a satisfactory fit between the simulations and measurements was observed for this output, and accumulated $\mathrm{N}_{\mathrm{up}}$ at the end of the crop predicted by the simulation with the non-calibrated and calibrated model were 19.960 and $14.466 \mathrm{~g} \mathrm{~N} \mathrm{~m}^{-2}$, respectively, compared with the measured value of $13.71 \mathrm{~g} \mathrm{~N} \mathrm{~m}^{-2}$. The calibrated parameters of this variable were a $=5.850$ and $b=-0.190$. According to the statistical values (Table 2), the BIAS the model overestimated $\mathrm{N}_{\text {up }}$ in the non-calibrated and calibrated model. However, the BIAS value near zero obtained by the calibrated model means that the quality of prediction improved considerably by calibration. In fact, the RMSE value decreased more than six times after calibration. In addition, EF values improved from 0.6 to 0.9 . Figure $5 \mathrm{~b}$ shows accurate predictions of $\mathrm{N}_{\text {up }}$ using the HortSyst model.

Figure 6 illustrates daily $\mathrm{N}_{\text {up }}$ concentration predicted by the model to show a potential use of the HortSyst model for predicting crop $\mathrm{N}_{\text {up }}$ concentration as a function of $\mathrm{ET}_{\mathrm{c}}$ for the autumn-winter crop cycle. For the first $20 \mathrm{~d}$ after transplanting

Figure 5. a) Time course of simulated and measured $N$ uptake $\left(\mathbf{N}_{\text {up }}\right)$ values with the calibrated and non-calibrated HortSyst model for a greenhouse tomato crop grown in Chapingo, Mexico. b) 1:1 plot for values simulated by the calibrated model and measured values.
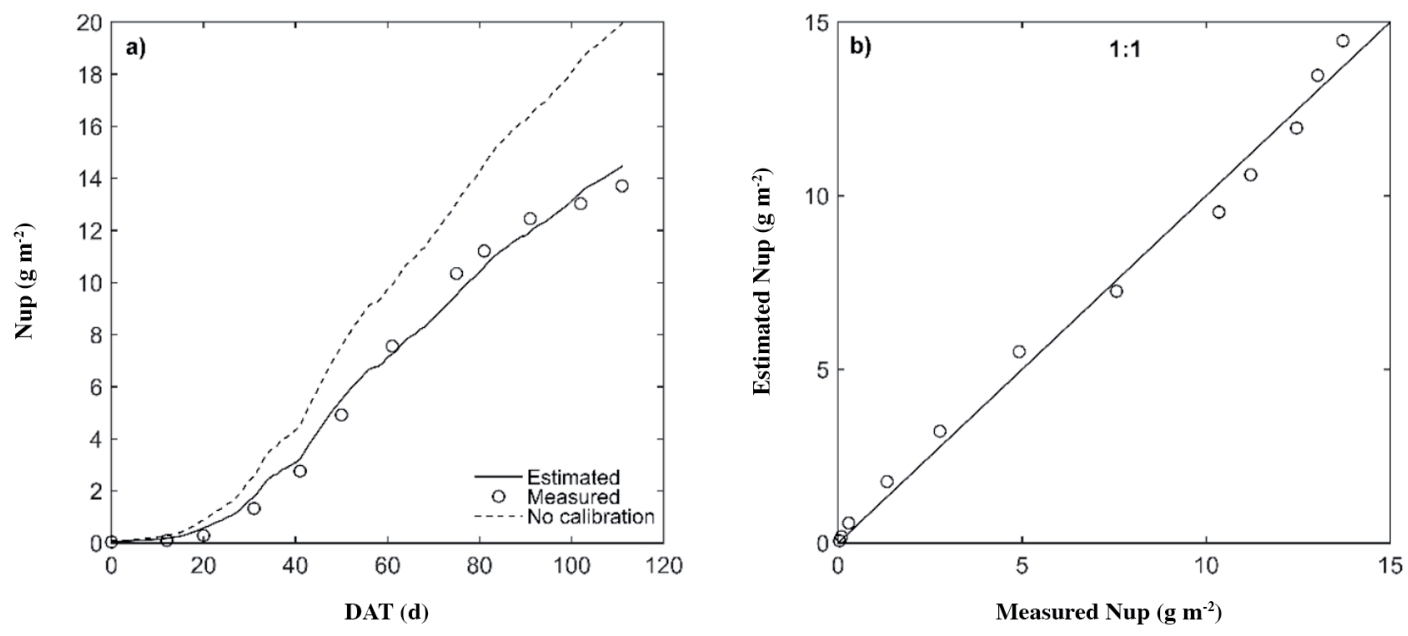

DAT: Days after transplanting.

Figure 6. Time course of simulated daily $\mathbf{N}$ concentration value during the 2015 autumn-winter season.

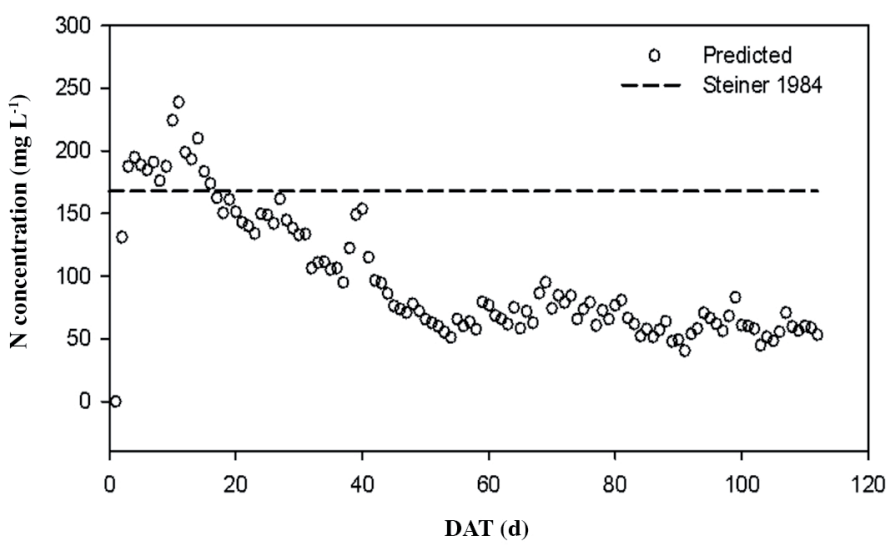

DAT: Days after transplanting. 
(DAT), crop $\mathrm{N}_{\text {up }}$ concentration exceeded the concentration of $168 \mathrm{mg} \mathrm{L}^{-1}$ recommended by Pineda-Pineda et al. (2009) and gradually decreased from 168 to $84 \mathrm{mg} \mathrm{L}^{-1}$ for 20-50 DAT; finally, the concentration decreased approximately half of the recommended concentration after 50 DAT (Figure 6). This means that more experiments are needed to evaluate this new recommendation of $\mathrm{N}$ application and compare this new result with the amount of $\mathrm{N}$ used by Pineda-Pineda et al. (2009). The performance evaluation of the model showed that if the model were applied, there would be savings of approximately $50 \%$ of applied fertilizer after 50 DAT when considering $100 \%$ efficiency of the production system under hydroponic culture, which means zero drainage management.

\section{Photo-thermal time (PTI)}

Figure 7a shows the PTI variable used by the HortSyst model to calculate LAI. The PTI behavior is similar to the one reported by Xu et al. (2010). Figure 7b illustrates the relationship between PTI and LAI by a Michaelis-Menten function. This PTI model satisfactorily predicted LAI using temperature and PAR radiation data; the calibrated parameter for this variable was the initial condition PTIini $\left(0.013 \mathrm{MJ} \mathrm{d}^{-1}\right)$. Accumulated PTI in the autumn-winter season was 105.271 $\mathrm{MJ} \mathrm{d}^{-1}$. The HortSyst model simulated PTI and LAI during the crop cycle, and this is the main difference between other models such as VegSyst and CropSyst (Confalonieri et al., 2010).

\section{Leaf area index (LAI)}

Given a lack of information in the literature for the parameters of these variables $\left(\mathrm{c}_{1}\right.$ and $\left.\mathrm{c}_{2}\right)$, a manual calibration was carried out to determine the possible values that could be used in the simulation for the growing period. Therefore, a pre-calibration was carried out with the MATLAB programming software to fit leaf area vs. PTI separate from the whole HortSyst model. The LAI variable played a central role in the model because it simulated the predicted PTI, DMP, and $\mathrm{ET}_{\mathrm{c}}$ values. The studied parameter values $\left(\mathrm{c}_{1}\right.$ and $\mathrm{c}_{2}$ ) are shown in Table 1 . The cumulative LAI values of the simulation at the end of the crop cycle for non-calibrated and calibrated models are quite similar to the measured values, which were $5.850,5.785$, and $5.780 \mathrm{~m}^{2} \mathrm{~m}^{-2}$, respectively (Figure 8a). The calibrated parameters of LAI were $\mathrm{c}_{1}=2.649$ and $\mathrm{c}_{2}=63.461$. According to BIAS, RMSE, and EF (Table 2), the performance behavior of the model with pre-calibration and calibration are the same, which means that the local calibration of the LAI sub-model had no effect on the global calibration of the VegSyst model. The low values for BIAS and RMSE as well as the EFF value of 0.99 indicated that the LAI predictions accurately follow measurements (Figure 8b).

Figure 7. a) Time course of photo-thermal time (PTI) predicted by HortSyst model, accumulated daily after transplanting for autumn-winter season. b) Relationship between PTI vs. leaf area index (LAI).
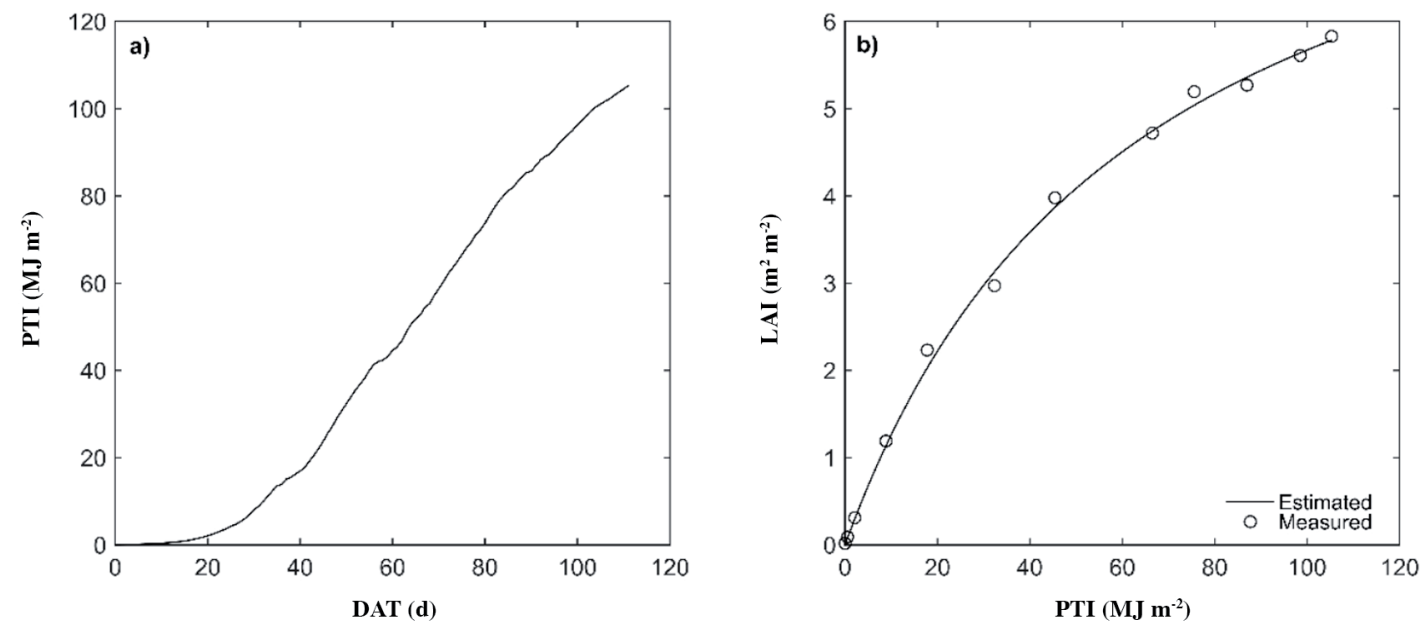

DAT: Days after transplanting. 
Figure 8. a) Time course of simulated and measured leaf area index (LAI) values with the calibrated and noncalibrated HortSyst model for a greenhouse tomato crop grown in Chapingo, Mexico. b) 1:1 plot for values simulated by the calibrated model and measured values.
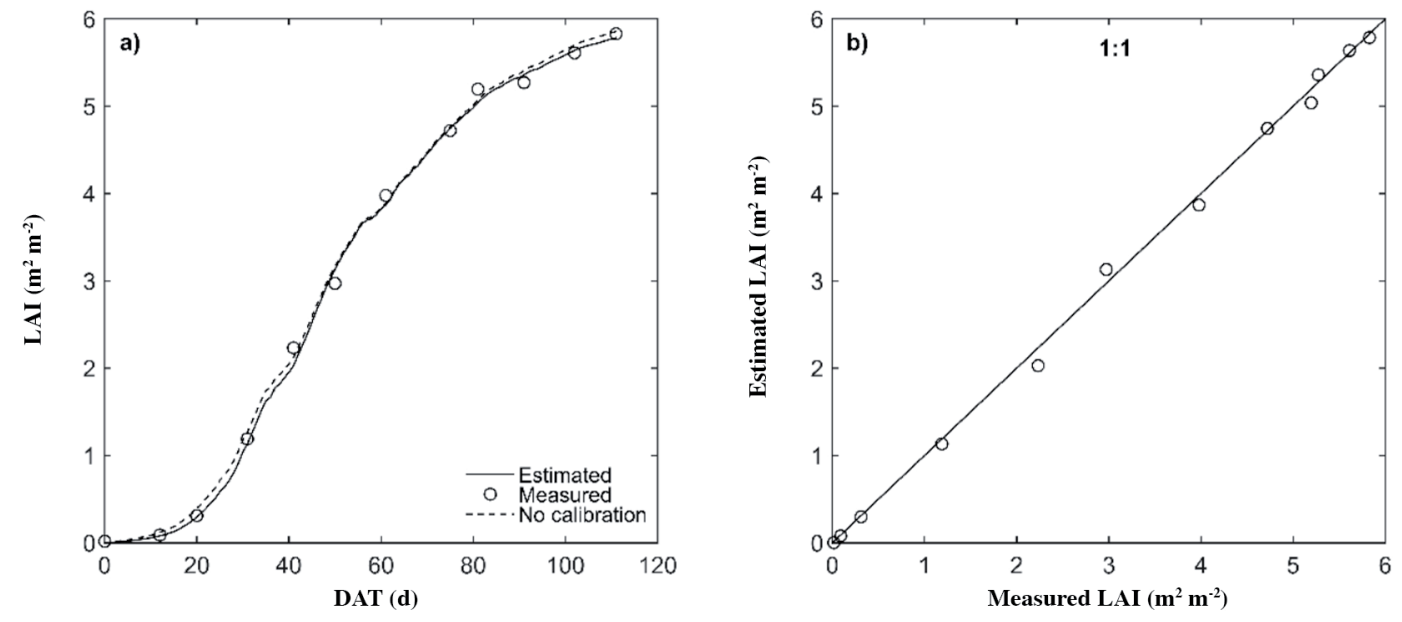

DAT: Days after transplanting.

\section{Crop transpiration $\left(\mathbf{E T}_{\mathrm{c}}\right)$}

Parameter values shown in Table 1 for $\mathrm{A}, \mathrm{B}_{\mathrm{d}}$, and $\mathrm{B}_{\mathrm{n}}$ were used and it was found that the goodness-of-fit statistics adopting the parameters reported in the literature were not satisfactory for the $\mathrm{ET}_{\mathrm{c}}$ variable in Figure 9a. This justifies model calibration aimed at greatly improving the statistics, and these parameters changed with calibration for A $(0.628), \mathrm{B}_{\mathrm{d}}$ (28.571), and $\mathrm{B}_{\mathrm{n}}$ (10.25). According to the BIAS statistic, the calibrated model improved more than six times. The RMSE was also lower in the case of the calibrated model. Moreover, modeling efficiency improved (Table 2). Accumulated water uptake at the end of the crop production period for the non-calibrated model was $108.970 \mathrm{~kg} \mathrm{~m}^{-2}$, the calibrated model was $197.262 \mathrm{~kg} \mathrm{~m}^{-2}$, and the measured value was $183.68 \mathrm{~kg} \mathrm{~m}^{-2}$. The calibrated simulation slightly underestimated $\mathrm{ET}_{\mathrm{c}}$ before 50 DAT and overestimated it after 50 DAT (Figure 9b), so when the crop had less than $3 \mathrm{~m}^{2} \mathrm{~m}^{-2}$ LAI, the prediction was accurate. To apply the model in irrigation scheduling, it is necessary to evaluate $\mathrm{ET}_{\mathrm{c}}$ hourly. A comparison of the measured and predicted transpiration by the calibrated HortSyst model is shown in Figure 10.

The recorded low level of radiation and temperature affected the reduction of accumulated total DMP, $\mathrm{N}_{\text {up }}$, and LAI, and high RH values reduced VPD, which directly affected $\mathrm{ET}_{\mathrm{c}}$.

Figure 9. a) Time course of simulated and measured evapotranspiration $\left(\mathbf{E} \mathbf{T}_{\mathrm{c}}\right)$ values with the calibrated and non-calibrated HortSyst model for a greenhouse tomato crop grown in Chapingo, Mexico. b) 1:1 plot for values simulated by the calibrated model and measured values.
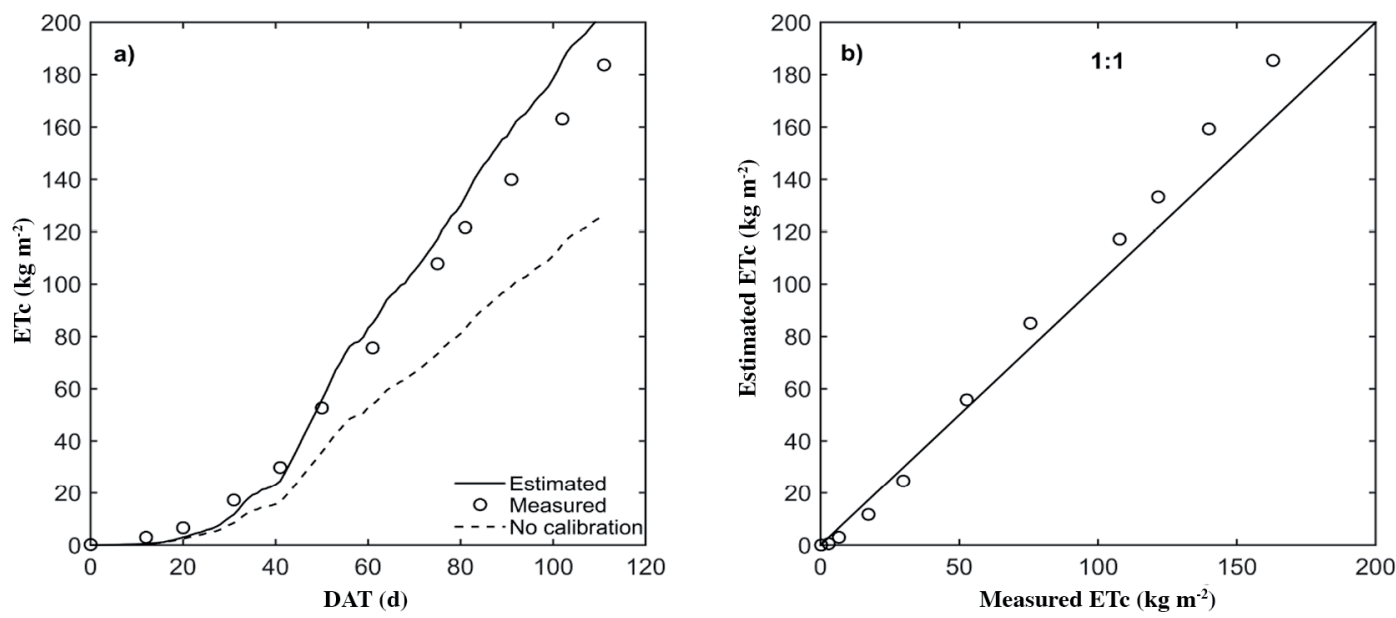

DAT: Days after transplanting. 
Figure 10. Time course of simulated and measured evapotranspiration (ETc) values calibrated from 13 to 30 September 2015 for a greenhouse tomato crop grown in Chapingo, Mexico.

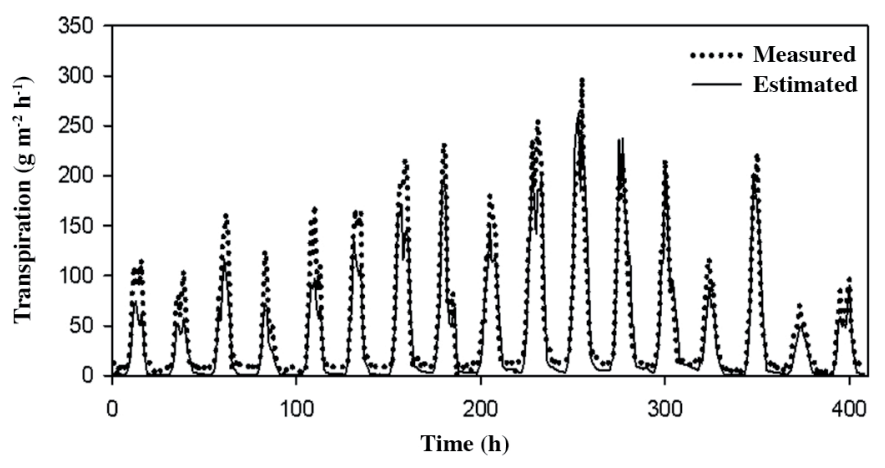

\section{DISCUSSION}

The HortSyst model accurately predicts DMP, PTI, and LAI; however, the quality of prediction of $\mathrm{N}_{\text {up }}$ and $\mathrm{ET}_{\mathrm{c}}$ is poor when using the nominal values of their parameters. After calibration, the model improved the predictive quality of $\mathrm{N}_{\text {up }}$ and $\mathrm{ET}_{\mathrm{c}}$ as well as of the other output variable parameter estimates using experimental data. Gallardo et al. (2016) obtained a RUE value of $4.01 \mathrm{~g} \mathrm{MJ}^{-1}$ in the simulation to predict DMP and reported that the quality of the simulated values was quite acceptable, but it was necessary to carry out the calibration to find the exact value of RUE. For this output, the values at the end of the cycle were slightly lower than values reported for autumn-winter by Gallardo et al. (2014). The RUE value from the calibrated model was $4.867 \mathrm{~g} \mathrm{MJ}^{-1}\left(\mathrm{~d}=3.5\right.$ plant $\left.\mathrm{m}^{-2}\right)$. It was higher than the $4.1 \mathrm{~g} \mathrm{MJ}^{-1}$ (density 2.0 plant $\mathrm{m}^{-2}$ ) value reported by Gallardo et al. (2014) and higher than the $3.0 \mathrm{~g} \mathrm{MJ}^{-1}$ value for the winter and summer found by Marcelis et al. (2009), and $1.05 \mathrm{~g} \mathrm{MJ}^{-1}\left(1.1 \mathrm{plant} \mathrm{m}^{-2}\right.$ ) and 1.89-2.44 $\mathrm{g} \mathrm{MJ}^{-1}$ reported by Tei et al. (2002). These RUE values are probably different due to differences in climatic conditions between one region and another and the agronomic management. The RUE value is also affected by vapor pressure (Gonias et al., 2012) and abiotic factors such as drought, low temperatures (Soltani and Sinclair, 2012), nutrient availability, crop growing location, and crop varieties (Muurinen and Peltonen-Sainio, 2006). Furthermore, $\mathrm{N}$ is the plant nutrient that most influences the RUE parameter. When comparing the RUE value between species with respect to photosynthetic processes, the $\mathrm{C} 4$ species has higher RUE than the C3 species (Muurinen and Peltonen-Sainio, 2006).

The amount of $\mathrm{N}$ extracted by the tomato crop because of the calibrated model at the end of the cycle was $14.466 \mathrm{~g} \mathrm{~N} \mathrm{~m}^{-2}$. This was half the quantity $\left(30 \mathrm{~g} \mathrm{~N} \mathrm{~m}^{-2}\right)$ of the spring-winter season reported by Gallardo et al. (2014) and 25-35 $\mathrm{g} \mathrm{N} \mathrm{m}^{-2}$ obtained by Elia and Conversa (2012); it is approximately equal to the measured value by Pineda-Pineda et al. (2009). The difference in the accumulated $\mathrm{N}_{\mathrm{up}}$ values at the end of the crop cycle was associated with the environmental conditions not being the same in each cycle, at least for radiation levels given the the location and perhaps temperature variation between day and night. In the present study, the non-calibrated model did not show a satisfactory fit, but reached all measured data when calibrated. The calibrated $\mathrm{N}$ content parameters were $\mathrm{a}=5.850$ and $\mathrm{b}=-0.190$; there is a decline in N\% with increased DMP and this followed a similar pattern across a range of crops. The value of parameter a was less than $\mathrm{a}=7.55$ found by Gallardo et al. (2014), the calibrated parameter $\mathrm{b}$ was slightly greater than $\mathrm{b}=-0.15$ (Gallardo et al., 2014), and less than $b=-0.25$ and $b=-0.36$ (Tei et al., 2002). These differences in parameters are probably due to crop variety, season, environmental conditions, and agronomic system management.

The modeling of LAI is one of the important differences of the HortSyst model compared with the VegSyst model because this variable is not included in the VegSyst model. However, several researchers (Soltani and Sinclair, 2012; Wallach et al., 2014) have recognized the relevance of LAI in crop growth models. It is now important to include this variable as a state or auxiliary variable to improve the performance of a new model. The final accumulated $\mathrm{ET}_{\mathrm{c}}$ value obtained by the calibration process for the autumn-winter season was $197.262 \mathrm{~kg} \mathrm{~m}^{-2}$ and near the value $(\sim 200 \mathrm{~mm})$ reported by Zotarelli et al. (2009) and Gallardo et al. $(2014 ; 2016)$ at 110 DAT. It is important to mention that the methodology by Gallardo et al. $(2014 ; 2016)$ to model water consumption was different. They used the Penman-Monteith model with 
growth coefficients; the disadvantage of this approach is that it does not allow irrigation scheduling in hydroponic culture because this system needs high frequency and low flow irrigation. Calibrated values for $A, B_{d}$, and $B_{n}$ were $0.628,28.571$, and 10.25, respectively. The calibrated value of parameter $A$ was less than $A=0.946$ found by Massa et al. (2011), greater than $A=0.372$ mentioned by Martinez-Ruiz et al. (2012), and similar to $A=0.59$ reported by Montero et al. (2001). The $B_{d}$ and $B_{n}$ parameters were less than $B=30$ (Martinez-Ruiz et al., 2012) and greater than $B_{d}(19.1)$ reported by Medrano et al. (2008) and Sánchez et al. (2011). The $B_{n}$ values were much lower than $B_{n}=26.0$ found by Medrano et al. (2008), and slightly higher than $B_{n}=8.5$ reported by Sánchez et al. (2011). The difference between calibrated parameters compared with the parameter values found in the reviewed literature is the simulation time of $\mathrm{ET}_{\mathrm{c}}$ because it is different in each research study. The transpiration model used in the HortSyst model by Medrano et al. (2005) found that the model does not fit very well for the autumn-winter season when the model was calibrated for a cucumber crop for the spring-summer and autumn-winter seasons. This concurs with the results obtained in the present study, and the problem is due to the low radiation level and VPD during the crop season.

As for PTI, Xu et al. (2010) found that modeling LAI using this concept provides better predictions than when using only the thermal time (TT) concept. The models based on TT could overestimate or underestimate LAI predictions because $\mathrm{R}_{\mathrm{g}}$ inside the greenhouse is not synchronized with the temperature behavior inside the greenhouse (Marcelis et al., 2009; Xu et al., 2010). On the other hand, when comparing estimated LAI with the specific leaf area used by CastañedaVera et al. (2015), it is a poor prediction due to the large variation of the specific leaf area between different growing seasons; the data of the specific leaf area variable can only be obtained by destructive measurements. This can limit the application of models based on specific leaf area of greenhouse crops and climate management practices (Xu et al., 2010). The advantage of using a mathematical model to make fertilization recommendations is that it considers factors such as environmental conditions, physiological processes $\left(\mathrm{ET}_{\mathrm{c}}\right.$ ), and crop characteristics (LAI and DMP). The model developed with estimated parameters showed $\mathrm{tN}$ concentration simulation results similar to those reported for the autumn-winter season by Gallardo et al. (2014), who evaluated the use of the VegSyst model under three fertilization recommendation scenarios.

\section{CONCLUSIONS}

The HortSyst model provides excellent predictive quality for dry matter production (DMP), $N$ uptake $\left(\mathrm{N}_{\mathrm{up}}\right.$ ), leaf area index (LAI), and evapotranspiration $\left(\mathrm{ET}_{\mathrm{c}}\right)$ with the estimated parameters. This is confirmed by the quality of the predictions shown in the previous figures and the statistical values of bias (BIAS), root mean square error (RMSE), and modeling efficiency (EF) found in the present study. Furthermore, the calibrated model showed optimal parameter values that have the best fit between predictions and measurements for the autumn-winter season of a tomato crop under hydroponic culture. Calibration of the HortSyst model was successful in finding the parameter values that helped to improve its predictive quality. The HortSyst model can be used as a decision-making tool in greenhouse production systems because, based on the simulation in the present study, it accurately predicts total DMP, $\mathrm{N}_{\mathrm{up}}, \mathrm{LAI}$, and $\mathrm{ET}_{\mathrm{c}}$. A new concept called photo-thermal time (PTI), which represents the effect of temperature on leaf expansion and the effect of radiation on crop growth, can be used to model LAI in crop models. Few models include the $\mathrm{ET}_{\mathrm{c}}$ variable in irrigation management; in the present study, a model derived from the simplification of Penman-Monteith was used and its simplicity can be used to predict crop water consumption. It also needs climatic variables that are commonly measured in greenhouses. However, more research is needed to improve the $\mathrm{ET}_{\mathrm{c}}$ model predictions for the autumn-winter cycle when radiation levels and VPD are low. It is necessary to evaluate the model with data from another experiment in a different crop cycle to evaluate its behavior under different scenarios. Due to the small number of parameters (13 parameters) involved in the HortSyst model, its use is feasible for irrigation management and $\mathrm{N}$ application in hydroponic tomato under greenhouse conditions.

\section{ACKNOWLEDGEMENTS}

The authors wish to thank the Universidad Autónoma Chapingo and CONACYT for funding this research as part of a $\mathrm{PhD}$ thesis. 


\section{REFERENCES}

Bacci, L., Battista, P., and Rapi, B. 2012. Evaluation and adaptation of TOMGRO model to Italian tomato protected crops. New Zealand Journal of Crop and Horticultural Science 40(2):115-126. https://doi.org/10.1080/01140671.2011.623706.

Barker, A.V., and Pilbeam, D.J. 2015. Handbook of plant nutrition. CRC Press, Boca Raton, Florida, USA.

Carmassi, G., Bacci, L., Bronzini, M., Incrocci, L., Maggini, R., Bellocchini, G., et al., 2013. Modelling transpiration of greenhouse gerbera (Gerbera jamesonii $\mathrm{H}$. Bolus) grown in substrate with saline water in a Mediterranean climate. Scientia Horticulturae 156:9-18. https://doi.org/10.1016/j.scienta.2013.03.023.

Castañeda-Vera, A., Leffelaar, P., Alvaro-Fuentes, J., Cantero-Martinez, C., and Minguez, M.I. 2015. Selecting crop models for decision making in wheat insurance. European Journal of Agronomy 68:97-116. https://doi.org/10.1016/j.eja.2015.04.008.

Chin, D.A., Fan, X.H., and Li, Y.C. 2011. Validation of growth and nutrient uptake models for tomato on a gravelly South Florida soil under greenhouse conditions. Pedosphere 21(1):46-55. https://doi.org/10.1016/S1002-0160(10)60078-1.

Chu, J.X., Sun,Z.F., Du, K.M., Jia, Q., and Liu, S. 2009. Establishment of dynamic model for the nutrient uptake and development about tomato in greenhouse. p. 54-58. In Cao, W., White, J.W., and Wang, E. (eds.) Crop modeling and decision support. Springer, Berlin, Heidelberg, Germany. https://doi.org/10.1007/978-3-642-01132-0_6.

Confalonieri, R., Bregaglio, S., and Acutis, M. 2010. A proposal of an indicator for quantifying model robustness based on the relationship between variability of errors and of explored conditions. Ecological Modelling 221(6):960-964. https://doi.org/10.1016/j.ecolmodel.2009.12.003.

Dai, J., Luo, W., Li, Y., Yuan, C., Chen, Y., and Ni, J. 2006. A simple model for prediction of biomass production and yield of three greenhouse crops. Acta Horticulturae 718:81-88. https://doi.org/10.17660/ActaHortic.2006.718.8.

Elia, A., and Conversa, G. 2012. Agronomic and physiological responses of a tomato crop to nitrogen input. European Journal of Agronomy 40:64-74. https://doi.org/10.1016/j.eja.2012.02.001.

Fourcaud, T., Zhang, X., Stokes, A., Lambers, H., and Körner, C. 2008. Plant growth modelling and applications: The increasing importance of plant architecture in growth models. Annals of Botany 101(8):1053-1063. https://doi.org/10.1093/aob/mcn050.

Gallardo, M., Fernandez, M.D., Giménez, C., Padilla, F.M., and Thompson, R.B. 2016. Revised VegSyst model to calculate dry matter production, critical $\mathrm{N}$ uptake and ETc of several vegetable species grown in Mediterranean greenhouses. Agricultural Systems 146:30-43. https://doi.org/10.1016/j.agsy.2016.03.014.

Gallardo, M., Thompson, R.B., Giménez. C., Padilla, F.M., and Stöckle, C.O. 2014. Prototype decision support system based on the VegSyst simulation model to calculate crop $\mathrm{N}$ and water requirements for tomato under plastic cover. Irrigation Science 32(3):237-253. https://doi.org/10.1007/s00271-014-0427-3.

Giménez, C., Gallardo, M., Martinez-Gaitán, C., Stöckle, C.O., Thompson, R.B., and Granados, M.R. 2013. VegSyst, a simulation model of daily crop growth, nitrogen uptake and evapotranspiration for pepper crops for use in an on-farm decision support system. Irrigation Science 31(3):465-477. https://doi.org/10.1007/s00271-011-0312-2.

Gonias, E.D., Oosterhuis, D.M., Bibi, A.C., and Roberts, B.A. 2012. Radiation use efficiency of cotton in contrasting environments. American Journal of Plant Sciences 3(5):649-654. https://doi.org/10.4236/ajps.2012.35079.

Lemaire, G., Oosterom, E., van Sheehy, J., Jeuffroy, M.H., Massignam, A., and Rossato, L. 2007. Is crop N demand more closely related to dry matter accumulation of leaf area expansion during vegetative growth? Field Crops Research 100(1):91-106. https://doi.org/10.1016/j.fcr.2006.05.009.

Marcelis, L.F.M., Elings, A., de Visser, P.H.B., and Heuvelink, E. 2009. Simulating growth and development of tomato crop. International Symposium on Tomato in the Tropics 821:101-110. https://doi.org/10.17660/ActaHortic.2009.821.10.

Martinez-Ruiz, A., López-Cruz, I.L., Ruiz-García, A., y Ramírez-Arias, A. 2012. Calibración y validación de un modelo de transpiración para gestión de riegos de jitomate (Solanum lycopersicum L.) en invernadero. Revista Mexicana de Ciencias Agrícolas 4:757-766.

Massa, D., Incrocci, L., Maggini, R., Bibbiani, C., Carmassi, G., Malorgio, F., et al., 2011. Simulation of crop water and mineral relations in greenhouse soilless culture. Environmental Modelling and Software 26(6):711722. https://doi.org/10.1016/j.envsoft.2011.01.004.

Medrano, E., Alonso, F.J., Sanchez-Guerrero, M.C., and Lorenzo, P. 2008. Incorporation of a model to predict crop transpiration in a commercial irrigation equipment as a control method for water supply to soilless horticultural crops. Acta Horticulturae 801:1325-1330.

Medrano, E., Lorenzo, P., Sánchez-Guerrero, M.C., and Montero, J.I. 2005. Evaluation and Modelling of greenhouse cucumber crop transpiration under high and low radiation conditions. Scientia Horticulturae 105(2):163-175. https://doi.org/10.1016/j.scienta.2005.01.024.

Montero, J.I., Antón, A., Muñoz, P., and Lorenzo, P. 2001. Transpiration from geranium grown under high temperatures and low humidities in greenhouses. Agricultural and Forest Meteorology 107(4):323-332. https://doi.org/10.1016/S0168-1923(01)00215-5.

Muurinen, S., and Peltonen-Sainio, P. 2006. Radiation use efficiency of modern and old spring cereal cultivars and its response to nitrogen in northern growing conditions. Field Crops Research 96(2-3):363-373. https://doi.org/10.1016/j.fcr.2005.08.009. 
Pineda-Pineda, J., Ramírez-Arias, A., Sánchez del Castillo, F., Castillo-Gonzáles, A.M., Valdez-Aguilar, L.A., and VargasCanales, J.M. 2009. Extraction and nutrient efficiency during the vegetative growth of tomato under hydroponics conditions. Acta Horticulturae 893:997-1005.

Rodríguez, F., Berenguel, M., Guzmán, J.L., and Ramírez-Arias, A. (eds.) 2016. Modeling and control of greenhouse crop growth. 250 p. Advances in Industrial Control. Springer International Publishing, Cham, Switzerland. doi:10.1007/978-3-319-11134-6.

Sánchez, J.A., Rodríguez, F., Guzmán, J.L., Ruiz Arahal, M., and Fernández, M.D. 2011 . Modelling of tomato crop transpiration dynamics for designing new irrigation controllers. Acta Horticulturae 893:729-738.

Shibu, M.E., Leffelaar, P.A., van Keulen, H., and Aggarwal, P.K. 2010. LINTUL3, a simulation model for nitrogen limited situations: Application to rice. European Journal of Agronomy 32(4):255-271. https://doi.org/10.1016/j.eja.2010.01.003.

Soltani, A., and Sinclair, T.R. 2012. Modeling physiology of crop development, growth and yield. Growth and yield. 322 p. CABI Publication, Wallingford, UK. https://doi.org/10.1079/9781845939700.0102.

Ta, T.H., Shin, J.H., Ahn, T.I., and Son, J.E. 2011. Modeling of transpiration of paprika (Capsicum annuum L.) plants based on radiation and leaf area index in soilless culture. Horticulture Environment and Biotechnology 52(3):265269. https://doi.org/10.1007/s13580-011-0216-3.

Tei, F., Benincasa, P., and Guiducci, M. 2002. Critical nitrogen concentration in processing tomato. In European Journal of Agronomy 18:45-55. https://doi.org/10.1016/S1161-0301(02)00096-5.

Vazquez-Cruz, M.A., Guzman-Cruz, R., Lopez-Cruz, I.L., Cornejo-Pérez, O., Torres-Pacheco, I., and GuevaraGonzalez, R.G. 2014. Global sensitivity analysis by means of EFAST ans Sobol' methods and calibration of reduced state-variable TOMGRO model using genetic algorithms. Computers and Electronics in Agriculture 100:1-12. https://doi.org/http://dx.doi.org/10.1016/j.compag.2013.10.006.

Wallach, D., Makowski, D., Jones, J.W., and Brun, F. 2014. Working with Dynamic Crop Models. Methods, tools and examples for agriculture and environment. $2^{\text {nd }}$ ed. 504 p. Academic Press-Elsevier, Cambridge, Massachusetts, USA. https://doi.org/10.1016/B978-0-12-397008-4.00008-3.

Xu, R., Dai, J., Luo, W., Yin, X., Li, Y., Tai, X., et al. 2010. A photothermal model of leaf area index for greenhouse crops. Agricultural and Forest Meteorology 150(4):541-552. https://doi.org/10.1016/j.agrformet.2010.01.019.

Zotarelli, L., Scholberg, J.M., Dukes, M.D., Muñoz-Carpena, R., and Icerman, J. 2009. Tomato yield, biomass accumulation, root distribution and irrigation water use efficiency on a sandy soil as affected by nitrogen rate and irrigation scheduling. Agricultural Water Management 96(1):23-34. https://doi.org/10.1016/j.agwat.2008.06.007. 